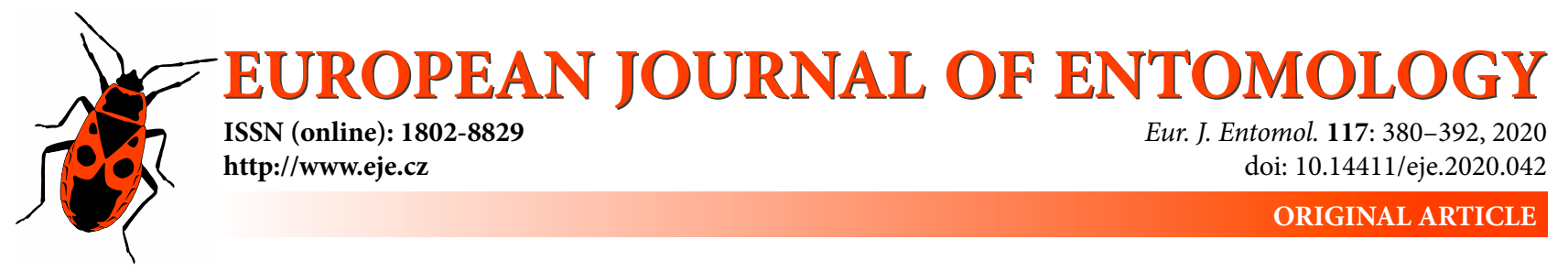

\title{
Asymmetry in host plant preferences of two ecotypes of Boloria eunomia (Lepidoptera: Nymphalidae)
}

\author{
Przemystaw KLIMCZUK and Marcin SIELEZNIEW
}

Laboratory of Insect Evolutionary Biology and Ecology, Faculty of Biology, University of Bialystok, Ciołkowskiego 1J, 15-245 Białystok, Poland; e-mails: bio_przemek@poczta.onet.pl, marcins@uwb.edu.pl

Key words. Lepidoptera, Nymphalidae, Boloria eunomia, ecotypes, larval survival, host plant, north-eastern Poland

\begin{abstract}
The diversity and evolution of host-plant relationships of butterflies has been the subject of much research. In this context, an interesting species is the bog fritillary Boloria eunomia. Across its boreo-montane distribution there are several ecotypes of this butterfly (sometimes distinguished as subspecies), which inhabit distinctly different habitats. However, little is known about the relationships between these forms in terms of host-plant use. We compared larval preferences of two ecotypes in north-eastern Poland, a unique region that is inhabited by different evolutionary lineages of $B$. eunomia. Larvae of the meadow ecotype reared in captivity were able to grow and develop exclusively on Persicaria bistorta, i.e., their 'native' host plant. In contrast, larvae originating from populations inhabiting raised bogs generally showed poorer survival, though they accepted both Ericaceae species growing in their biotope and $P$. bistorta, a plant that does not occur in their biotope. They did not show clear food preferences, but mortality was lowest when they were fed Vaccinium uliginosum. This is puzzling as field observations indicate that Vaccinium oxycoccus is the main host plant in the area studied. However, our findings are consistent with the results of phylogeographical studies indicating that meadows were the ancestral habitats of $B$. eunomia and some populations adapted later to different biotopes. The poor survival of larvae of the bog ecotype recorded in the present study may indicate that this form is at least locally potentially more vulnerable than the other ecotype.
\end{abstract}

\section{INTRODUCTION}

The question of butterfly larval food preferences and the level of their specialization has been widely studied. Butterflies strongly depend on the distribution of particular species of plants and some species additionally require a specific habitat (e.g. Grundel et al., 1998; Bergman, 1999). There are different levels of host plant specialization ranging from polyphagy to monophagy. Polyphagous species can use many plants belonging to different families and/or orders (e.g. Nylin, 1988; Janz, 2005). Oligophagous species feed on several closely related plants, i.e., belonging to a single family (e.g. Burghardt \& Fiedler, 1996; Cleary et al., 2002). Finally, monophagy is marked by an ability to feed only on one species of plant or, in a broader context, several plants belonging to one genus. Monophagy should be treated carefully, and there are examples of descriptions of new larval host plants for butterflies previously considered as monophagous on a global or regional scale (e.g. Döring \& Hoffmann, 2004; Švitra \& Sielezniew, 2010). Within a single species, host use sometimes differs regionally, simply in relation to the distributions of potential larval food plants, but this may also be connected with additional local factors (Quinn et al., 1998; Martin \& Pullin, 2004). Moreover, species considered generally as poly- or oligophagous can be monophagous at a local scale (Meister et al., 2015).

It is suggested that host-plant specialization evolved as an adaptation to different and changing environmental conditions (Thompson \& Pellmyr, 1991; Joshi \& Thompson, 1995). Usually, adapting to particular host plants and/ or niches is a long-term process. Nevertheless, some cases of rapid host shifts caused mainly by introduction of nonnative species of plants are documented (e.g. Graves \& Shapiro, 2003; Gillespie \& Wratten, 2011; Singer \& Parmesan, 2018).

The bog fritillary Boloria eunomia (Esper, 1799) is an interesting species in the context of the evolution of larval preferences. This holarctic boreo-montane butterfly inhabits raised peat bogs and wet meadows both in lowlands and subalpine/alpine habitats. The list of larval food plants of B. eunomia cited in the literature includes species belonging to Polygonaceae, Ericaceae, Violaceae and Salicaceae (Shepard, 1975; Laplante, 1985; Tolman, 1997; Nekola, 1998; Haahtela et al., 2006; Turlure et al., 2009; Noreika et al., 2016). Taking this into consideration, the bog fritillary might be formally qualified as a polyphagous species. Nevertheless, there are several ecotypes of this butterfly that are sometimes described as subspecies strictly adapt- 
ed to particular habitats and host plants. In Europe, two main forms may be distinguished. The first is the meadow ecotype, also described as B. eunomia eunomia, which inhabits wet meadows and fens and common bistort Persicaria bistorta is the only larval host plant. Most of the information on the biology of this ecotype comes from numerous studies carried out in the Ardennes (e.g. Choutt et al., 2011; Radchuk et al., 2013). The second ecotype, often recognized as $B$. eunomia ossiana, occurs on raised bogs, mires and in boggy pine forests, and four Ericaceae species are cited as the larval host plants in these biotopes (Noreika et al., 2016). The real importance of each of these plants is unknown and some field observations, both on oviposition and larval behaviour, indicate that Vaccinium oxycoccus could be locally preferred (Klimczuk \& Sielezniew, 2017 and unpubl.). Moreover, little is known about the relationships between the meadow and bog form in the context of the potential ability of their larvae to feed on different species of plants.

In this paper, we present results of studies carried out on stock obtained in an area in north-eastern Poland where both ecotypes co-occur (Klimczuk, 2011; Sielezniew et al., 2019). We aimed to compare feeding preferences as well as the development and survival of larvae of both ecotypes reared in captivity on different plants ('native' and 'nonnative' to their habitats) in the pre-winter phase. In addition, we tested larval preferences for plants of different heights and the ability of larvae to move vertically and between potential hosts.

\section{MATERIALS AND METHODS}

\section{Larvae}

Larvae used in the experiments were obtained from eggs laid by females caught (using a net) at several sites in north-eastern Poland. Females of the meadow ecotype originated from three populations in the Knyszyn Forest (Woronicza, Straszewo, Sokole) and those of the bog ecotype from two other localities in the Knyszyn Forest (Jesionowe Góry and Widły) and one in the Augustów Forest (Skieblewo). The females of B. eunomia are easily distinguishable from males and mate immediately after emergence, thus it is highly probable that when caught they were already fertilized. They were kept at room temperature $\left(20-25^{\circ} \mathrm{C}\right)$ in small plastic containers (about $160 \mathrm{~cm}^{3}$ ) containing plants relevant to the given ecotype, i.e., with common bistort or bog cranberry. Small boxes that limit the activity of the females are recommended for getting them to lay eggs (Buszko, 1997). Every day females were fed a solution of water and honey and at the end of each day they were transferred to new containers, whereas the eggs were collected and grouped by date and ecotype. At night, the containers with females were kept in a refrigerator at a temperature of about $6-8^{\circ} \mathrm{C}$ in order to reduce activity and so prolong their life.

The eggs were kept at room temperature $\left(20-25^{\circ} \mathrm{C}\right)$ until they hatched. In 2017, we obtained a total of 80 larvae of the meadow ecotype and 208 larvae of the bog ecotype. In 2018, the number of larvae used in the experiments was 439 and 417, respectively. In 2018 , the adults of $B$. eunomia flew earlier in the year and as a consequence they laid eggs and the larvae hatched earlier (between June 9 and June 25) than in 2017 (between June 26 and July 3).

\section{Larval survival and development prior to overwintering}

Directly after hatching, larvae were grouped by age and placed in a plastic container (max. up to 30 individuals per container) and supplied with only one potential host plant species ('native' or 'alien' for a given ecotype) (see Fig. S1). All other conditions were the same for all groups. Containers were examined every 2-5 days, larvae were counted, marks on leaves indicating feeding were recorded, dead larvae and frass were removed, old plants were replaced with fresh ones, and a paper towel lining the bottom of the containers was dampened. Rearing was carried out in a room at $20-25^{\circ} \mathrm{C}$ in 2017 . The following year a lower temperature was used $\left(20-22^{\circ} \mathrm{C}\right)$ in order to increase the expected survival of the larvae of the bog ecotype. Finally, containers were transferred outside the building on September 1 in 2017 and September 22 (after the last heat wave) in 2018 and kept under natural temperature conditions, but protected from direct sunlight.

The plants used in the rearing experiments included common bistort Persicaria bistorta (Polygonaceae, Caryophyllales) the native host of the meadow ecotype (Turlure et al., 2009) and bog cranberry Vaccinium oxycoccus, bog whortleberry V. uliginosum and bog rosemary Andromeda polifolia (Ericaceae, Ericales) the native food plants of the bog ecotype (Noreika et al., 2016). In addition, marsh violet Viola palustris and eared willow Salix aurita (Violaceae and Salicaceae respectively, Malpighiales) were used as both $V$. palustris and Salix spp. are recorded as host plants of the larvae (Shepard, 1975; Scott, 1986; Bird et al., 1995; Tolman, 1997; Haahtela et al., 2006). The ability of the larvae to feed on common bilberry Vaccinium myrtillus and marsh Labrador tea Rhododendron tomentosum (=Ledum palustre) was also determined. Both these species belong to the Ericaceae, but are not recorded as host plants. Finally, larvae were offered the common dandelion Taraxacum officinale (Asteraceae), which is a host of many species of Lepidoptera and is often used to feed unknown larvae in captivity (Buszko, 1997). Only plants that occur in north-eastern Poland were used in this study, therefore, alpine bistort Persicaria vivipara (Polygonaceae) was not tested, though it is reported as a host plant (Shepard, 1975; Scott, 1986; Tolman, 1997; Layberry et al., 1998).

\section{Host plant selection}

The host plant selection tests were carried out using newly hatched larvae that had not previously fed. Four species of plants (P. bistorta, V. oxycoccus, V. uliginosum and A. polifolia) were presented to larvae of both ecotypes. In addition, food preferences of larvae of the meadow ecotype provided with two species of plants, $P$. bistorta and V. palustris, were determined (Fig. S2).

Whole or fragments of fresh leaves were placed in 9-cm Petri dishes lined with a dampened paper towel. The leaves were placed in similar circle-like areas arranged equidistantly around the edge of the dish. Then, larvae of a given ecotype were placed in the centre of the dish. The first two trials with the bog ecotype and the first one with the meadow ecotype were completed using 30 larvae. In the following trials the availability of larvae was limited and only 15 larvae were used in each trial. Location of larvae relative to the plants offered was checked after 2, 24, 48 and $72 \mathrm{~h}$ and percentage of individuals on the plants or directly under the leaves was recorded. In addition, evidence of feeding was recorded using a four-point scale $(0$ - none, 1 - minor, 2 - small to medium, 3 -marked). A rough measure was used as the shape and thickness of the leaves of the different species of plants differed.

Six trials, each using four species of plants were carried out for larvae of the bog ecotype. In the case of the meadow ecotype there were three trials each using four species of plants and three trials with two species of plants. 


\section{Ability of larvae to move vertically and their food preferences}

In order to determine the ability of larvae of the bog ecotype to move vertically between different host plants, there were five trials using second, third or fourth instar larvae in 2018. Before the tests, the larvae, which originated from females caught in the Augustów Forest, were fed $V$. uliginosum.

The bottom of a $13 \mathrm{~cm}$ diameter beaker with a capacity of 2 $\mathrm{L}$ was lined with a dampened paper towel on which there were fresh, leafy shoots of $V$. oxycoccus. In the centre of this beaker was placed a small bottle containing water and fresh shoots of V. uliginosum (20 to $28 \mathrm{~cm}$ tall). The bottle was tightly wrapped in a paper towel and its opening plugged to avoid the accidental drowning of larvae. To prevent the larvae from falling they were placed on a small paper tray glued to a plant. The top of the beaker was then tightly covered with a transparent plastic wrap to prevent the larvae leaving the beaker. The $V$. uliginosum leaves were at least about $10 \mathrm{~cm}$ above the bottom of the beaker (Fig. S3).

There were two versions of this experiment: 10 larvae were placed (i) on $V$. uliginosum at a height of 15 or $20 \mathrm{~cm}$ or (ii) on $V$. oxycoccus about $2 \mathrm{~cm}$ above the bottom of the beaker. Distribution of larvae was recorded after $24 \mathrm{~h}$. Each version of this experiment was replicated twice.

In addition, in one test larvae were placed on $V$. uliginosum in the absence of $V$. oxycoccus.

\section{Food preferences of larvae of the bog ecotype after overwintering}

Some final instar larvae of the bog ecotype were collected at the end of April 2014 at Jesionowe Góry. They were divided into two groups fed different plants (i.e. $V$. oxycoccus and P. bistorta) and reared in the laboratory at room temperature $\left(20-25^{\circ} \mathrm{C}\right)$. The observations were used as a basis for the studies on the survival and food preferences of the larvae that were carried out in 2017 and 2018 .

\section{Statistical methods}

Survival of larvae of both ecotypes reared on a single plant species over a period of 100 days from the day of hatching was compared. Larval life span was measured in days. The MannWhitney U test was used to compare survival of larvae reared on individual plants. This non-parametric test was used as the data were not normally distributed except for one group and due to a lack homogeneity of variance in individual groups (both ShapiroWilk test and Levene's test were statistically significant). In addition, the sizes of the groups of larvae reared on individual plants were not the same.

The similarity of duration of development and survival of larvae of the meadow ecotype fed $P$. bistorta and larvae of the bog ecotype reared on $V$. oxycoccus, $V$. uliginosum, A. polifolia and $P$. bistorta, was checked using hierarchical cluster analysis. Twelve measurements were recorded over one hundred days $(0,5,10$, $20,30 \ldots 100$ days) and used to make two dendrograms. The first dendrogram was based on survival (number of larvae still alive) and the second on both survival and the number of individuals in consecutive stages of development. Both profiles clearly showed the distinct position of the larvae of the meadow ecotype, whereas the distances between the four groups of larvae of the bog ecotype were markedly shorter and in the survival dendrogram these four groups were even in the same cluster. Thus, individuals of the bog ecotype were pooled into one group.

In the case of the host plant selection tests, the non-parametric Mann-Whitney U and Kruskal-Wallis tests were used. The reason was that the data was not normally distributed for the majority of groups. Comparisons of two parameters ('percentage of larvae on plants' and 'evidence of feeding') were made in corresponding pairs and groups. In addition, for the quantitative variable 'percentage of larvae on plants' (when four species of plants were provided), a general linear model for repeated measures was used and tests of between subject effects were taken into account.

In the 'vertical movement' experiment, three zones were distinguished: initial (where larvae were initially placed), intermediate (between plants) and different (had moved from one plant to the other). A chi-squared test was used to compare two versions (and one additional) of the experiment in respect of: (i) the number of larvae in particular zones after $24 \mathrm{~h}$, (ii) the number of larvae that had changed their location after $24 \mathrm{~h}$.

PS IMAGO PRO (IBM SPSS Statistics) was used for the statistical analysis.

\section{RESULTS}

\section{Larval survival and development prior to overwintering}

The larvae of both ecotypes differed significantly in their survival and ability to feed on the plants provided (Table 1, S1, Fig. 1). The larvae of the meadow ecotype only developed successfully on P. bistorta. They also fed on V.palustris, but their growth was very slow and only two of 94 violet-fed larvae reached the second instar after more than two weeks and they finally died on the 30th and 50th day of life. However, the larvae of the bog ecotype developed on plants native for this ecotype, $V$. oxycoccus, A. polifolia and $V$. uliginosum, as well as on $P$. bistorta. In addition, they grew on $V$. myrtillus with $53 \%$ and $24 \%$ of the larvae reaching the second and third instar, respectively. Their maximum life span was 50 days. Both the larvae of the meadow and the bog ecotypes started feeding on $S$. aurita, but did not grow and remained in the first instar for up to 22 days.

Larvae of the meadow ecotype reared on P. bistorta had the highest survival of all groups of larvae tested (Fig. 1). The percentage of larvae that survived for a long time was high and similar in both seasons $(\mathrm{U}=3492.5, \mathrm{p}=0.185)$. The survival of the larvae of the bog ecotype was generally worse and differed on the different species of plants. In the case of 'native' plants for this ecotype, the larvae reared on $V$. oxycoccus had the highest mortality, whereas those reared on $V$. uliginosum survived best $(\mathrm{U}=1181.5$, $\mathrm{p}=0.014$ in 2017 and $\mathrm{U}=6592.0, \mathrm{p}=0.001$ in 2018). Furthermore, a fairly good survival of the larvae of the bog ecotype on P. bistorta was recorded. This was particularly evident in 2017, when it was comparable to the survival of the $V$. uliginosum-fed larvae $(\mathrm{U}=1284.0, \mathrm{p}=0.772)$.

In addition to inter-season variability, there were significant differences between the two ecotypes in the development and activity of larvae in the pre-wintering period (Figs $2,3)$. In the case of the meadow ecotype, all larvae reared on $P$. bistorta in both years underwent the first moult after 3-10 days, and all except one larva reached the third instar 11-19 days after hatching and continued feeding until they were 20-30 days old, after which they ceased feeding. In 2017, a few larvae consumed a minor amount of the $P$. bistorta leaves provided when approximately 80 days old. All the larvae overwintered in the third instar. In contrast 
A

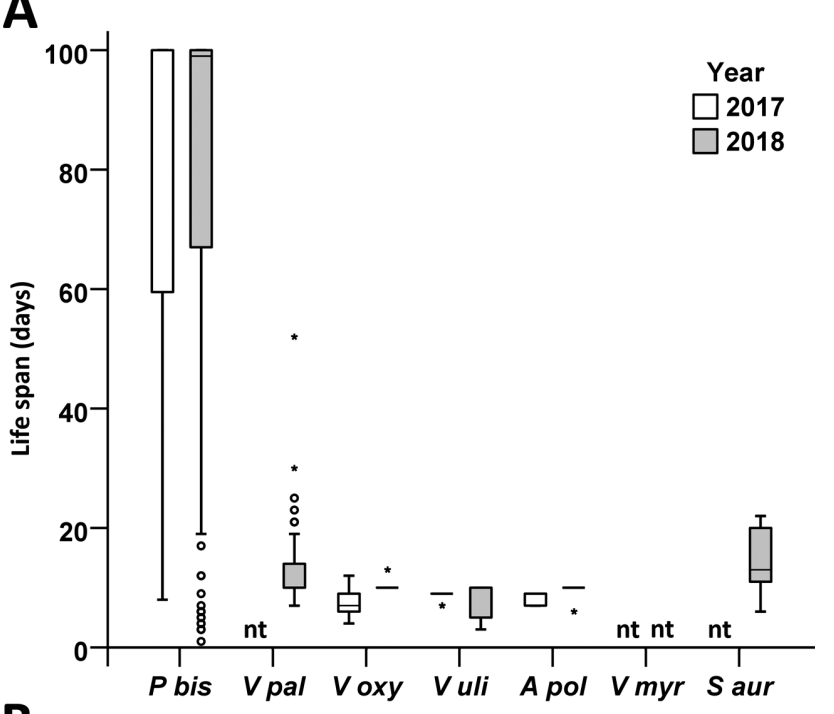

B

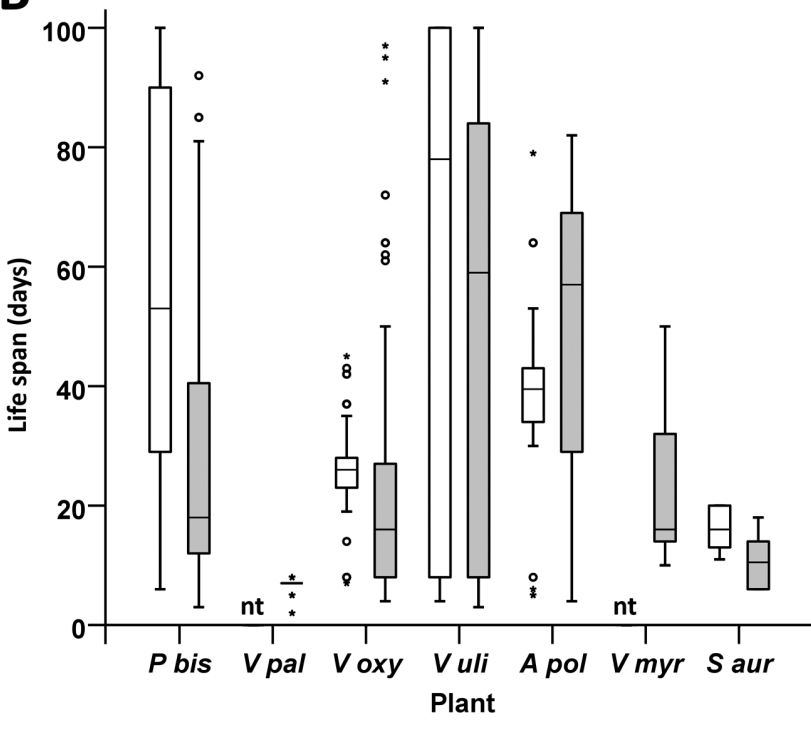

Fig. 1. Prewinter life span of larvae of the (A) meadow and (B) bog ecotypes of Boloria eunomia reared on different species of plants. $P$ bis - Persicaria bistorta, V pal - Viola palustris, V oxy - Vaccinium oxycoccus, $V$ uli - Vaccinium uliginosum, $A$ pol - Andromeda polifolia, V myr - Vaccinium myrtillus, $S$ aur - Salix aurita, nt - not tested.

in 2018 , the majority of the larvae resumed activity when 48-98 days old and 16 of them moulted to the fourth instar. Most of them re-entered diapause after a few days, but three larvae continued to feed intensively and moulted to the fifth instar. They completed development and two of them pupated when 93 and 104 days old, respectively, and two adult females of the second generation emerged 9 and 11 days later (September 26 and October 7).

The development of the larvae of the bog ecotype was different, but varied little on the four plants provided ( $V$. oxycoccus, $V$. uliginosum, $A$. polifolia and $P$. bistorta). The first and second moult occurred less synchronously than recorded for the meadow ecotype (especially in the case of cranberry-fed larvae), i.e., 4-20 and 16-30 days after hatching, respectively. The larvae were still active in the third instar and some of them moulted again between the
Table 1. Ability of larvae of two ecotypes of Boloria eunomia to feed and develop on different species of plants. $\mathrm{N}$ - initial number of larvae tested in 2017/2018, +/- - limited development, nt - not tested, * cases, when larvae fed and moulted two or more times.

\begin{tabular}{|c|c|c|c|c|c|c|}
\hline \multirow[b]{2}{*}{ Plant species } & \multicolumn{3}{|c|}{ Meadow ecotype } & \multicolumn{3}{|c|}{ Bog ecotype } \\
\hline & $\mathrm{N}$ & Feeding & $\begin{array}{c}\text { Develop- } \\
\text { ment }\end{array}$ & $\mathrm{N}$ & Feeding & $\begin{array}{c}\text { Develop- } \\
\text { ment }\end{array}$ \\
\hline P. bistorta & $27 / 302$ & $+^{*}$ & $+^{*}$ & $73 / 88$ & $+^{*}$ & $+^{*}$ \\
\hline V. palustris & $0 / 94$ & + & $+1-$ & $0 / 32$ & - & - \\
\hline V. oxycoccus & $33 / 10$ & - & - & $53 / 130$ & $+^{*}$ & $+^{*}$ \\
\hline A. polifolia & $11 / 10$ & - & - & $30 / 49$ & $t^{*}$ & $+^{*}$ \\
\hline V. uliginosum & $9 / 7$ & - & - & $34 / 79$ & $+^{*}$ & $+^{*}$ \\
\hline V. myrtillus & $0 / 0$ & $\mathrm{nt}$ & nt & $0 / 17$ & $+^{*}$ & $+1-*$ \\
\hline S. aurita & $0 / 6$ & + & - & $16 / 14$ & + & - \\
\hline R. tomentosum & $0 / 0$ & nt & nt & $0 / 3$ & - & - \\
\hline T. officinale & $0 / 10$ & - & - & $0 / 5$ & - & - \\
\hline
\end{tabular}

ages of 25 and 68 days. In 2017, 16 out of 121 third instar larvae reached the fourth instar, whereas in the following year, it was 52 out of 124 . On the hundredth day of life in $2017,55 \%$ of the larvae were in the fourth instar, whereas
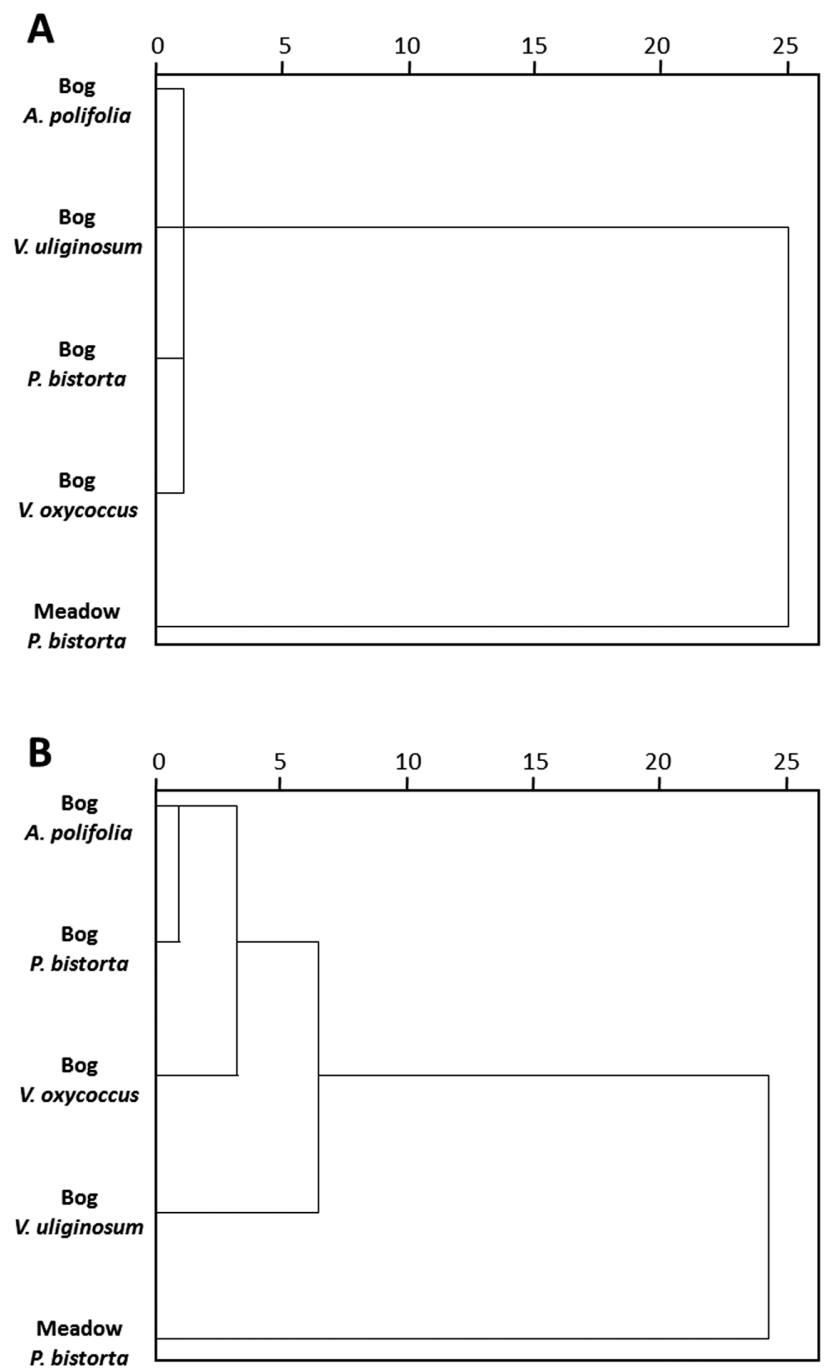

Fig. 2. Differences in larval survival over the first 100 days of their life in 2018 without (A) and with (B) the number of individuals in consecutive stages of development included based on an hierarchical cluster analysis. Five groups of larvae were tested. Bog - bog ecotype, Meadow - meadow ecotype. See Table S5 for appropriate distance matrix. 
A

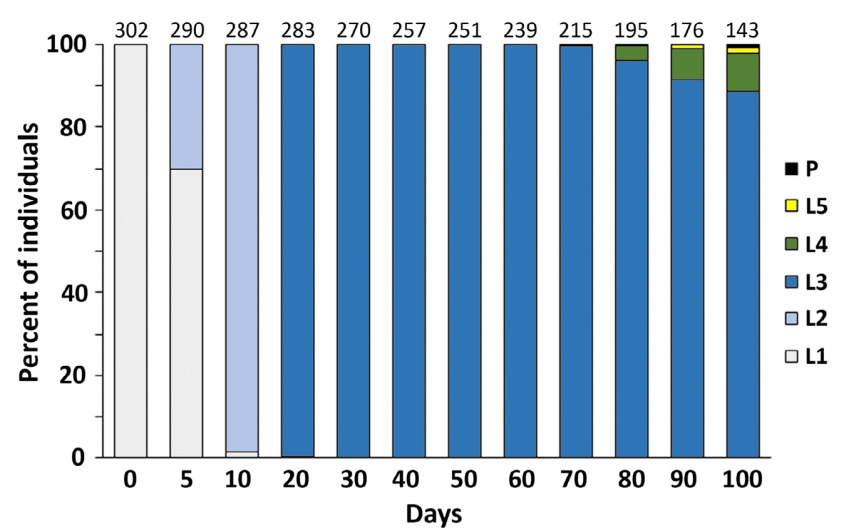

B

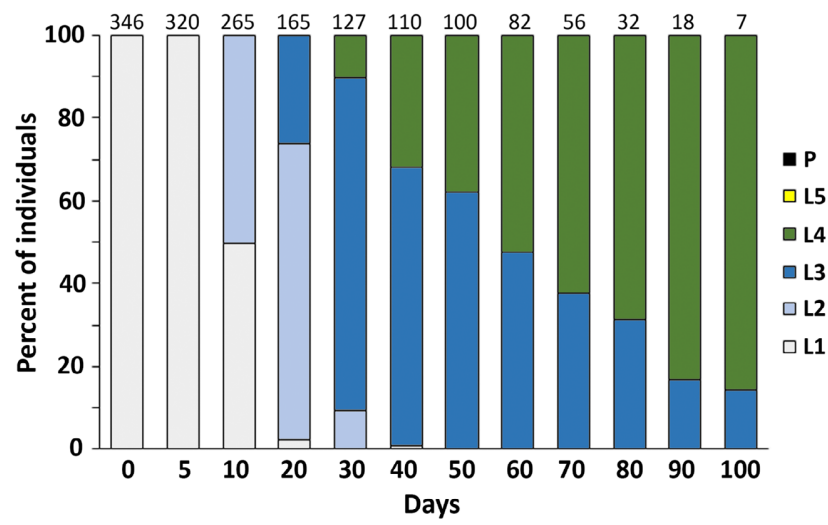

Fig. 3. Percentage of individuals of Boloria eunomia of the $(A)$ meadow and $(B)$ bog ecotypes in successive stages of development over a period of 100 days from hatching in 2018. L1, L2... - larval instars, P - pupa. In the case of the bog ecotype individuals reared on four plants (Vaccinium uliginosum, V. oxycoccus, Andromeda polifolia, and Persicaria bistorta) are pooled. Figures above bars indicate the number of individuals still alive.

in 2018 it was $86 \%$, but none moulted to the fifth instar. For comparison, at that age, most of larvae of the meadow ecotype were in the third instar, i.e., $100 \%$ in 2017 and $89 \%$ in 2018. The summer activity of larvae of the bog ecotype was variable. It was difficult to assess whether they had already entered diapause, since minor evidence of feeding on the leaves were recorded in late September when they were 90 and 104 days old in 2017 and 2018, respectively.

During the rearing experiments, high larval mortality or weakness was associated with at least three factors: fungus and viral disease (especially in 2018) and digestive disorders (primarily manifested by frass stuck in the anus) mainly recorded in the violet-fed larvae.

\section{Host plant selection}

The experiments revealed marked differences between the larvae of two ecotypes in terms of both the number of individuals staying on plants and the area of the leaves consumed (Figs 4-6, Table S2, S3). Initially, larvae moved from the centre of the Petri dish in a random manner not related to the choice of a particular plant. After just two hours some of them began to feed. Differences were recorded after 24, 48 and $72 \mathrm{~h}$. In the case of the meadow

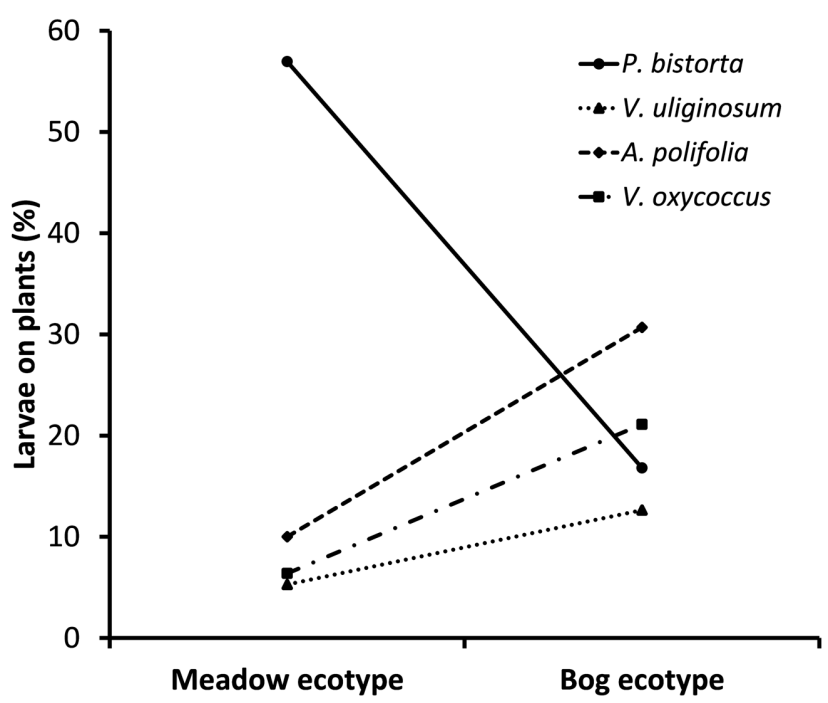

Fig. 4. Differences in estimated marginal means for percentages of larvae of two ecotypes recorded on four plants in the 'host plant selection test'. Tests of between subject effects (in general linear model for repeated measures) revealed highly significant differences between the two ecotypes in relation to plants $(F=7.159$, $\mathrm{df}=3, \mathrm{p}=0.001)$ and the ecotype $\mathrm{x}$ plant interaction $(\mathrm{F}=9.362$, $\mathrm{df}$ $=3, p<0.001)$.

ecotype, the highest number of larvae was always recorded on $P$. bistorta, while the percentage of larvae on the other plants decreased over time (Fig. 5A). P. bistorta was the only plant on which they fed while no evidence of feeding was detected on other plants (Fig. 6A).

On the other hand, in the case of the bog ecotype, there was no regularity in terms of the percentage of larvae staying on plants or area of leaf consumed (Figs 5B, 6B). However, although the larvae did not prefer a particular species of plant, they usually chose the young leaves of $V$. oxycoccus and A. polifolia.

When larvae of the meadow ecotype were offered P. bistorta and $V$. palustris, they fed almost exclusively on the former plant, which is consistent with results in terms of survival. Minor evidence of feeding on a leaf of $V$. palustris was recorded only in one of the three tests. Differences in both the percentage of larvae remaining on plants and the area of leaves consumed became highly significant after 24, 48 and 72 h (Fig. 7, Table S4).

\section{Ability of larvae to move vertically and their food preferences}

In two trials, when larvae of the bog ecotype were initially placed in the upper zone (on $V$. uliginosum), five and six of the ten larvae were recorded in the lower, $V$. oxycoccus zone after $24 \mathrm{~h}$. Evidence of feeding were recorded on both host plants. When larvae were initially placed on $V$. oxycoccus (the lower zone), only one individual moved upwards into the $V$. uliginosum zone $(18$ or $18.5 \mathrm{~cm})$ in each trial. In addition, in one trial a single larva remained between $V$. uliginosum and $V$. oxycoccus zones at a height of $10 \mathrm{~cm}$. Most of the larvae remained close to the bottom $(1.5$ to $6 \mathrm{~cm})$. There were statistically significant differences between the two versions of the experiment both in terms of the number of larvae remaining in zones after $24 \mathrm{~h}$ 

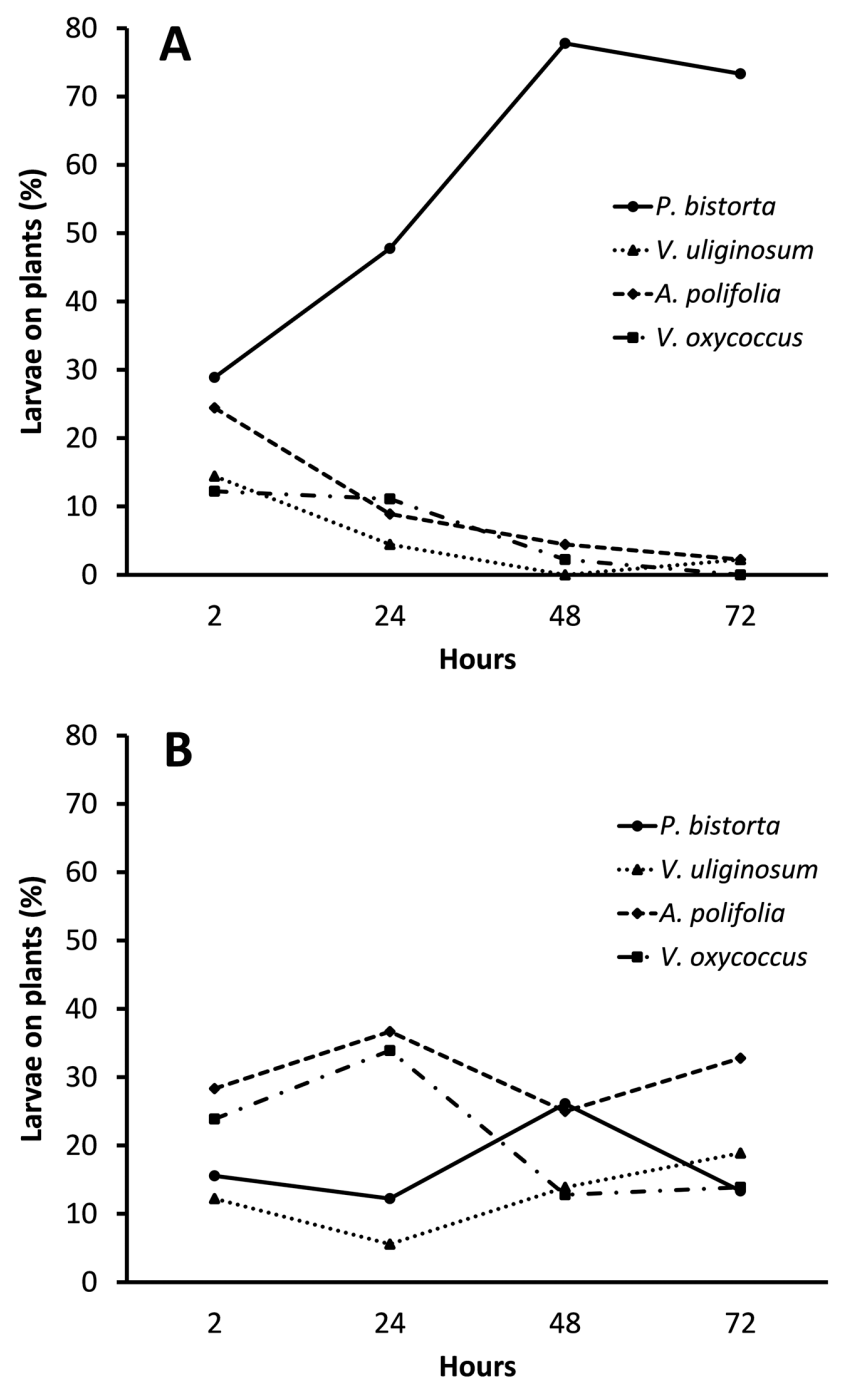

Fig. 5. Changes in the percentage of larvae (estimated marginal means) of the (A) meadow and (B) bog ecotypes present on plants during the 'host plant selection test'.

$\left(\chi^{2}=6.740, \mathrm{df}=2, \mathrm{p}=0.034\right)$ and the number of larvae that moved to a different zone $\left(\chi^{2}=7.033, \mathrm{df}=1, \mathrm{p}=0.008\right)$.

Downward movement in the test in which there was no $V$. oxycoccus at the bottom of the beaker, was not significantly different from that recorded when $V$. oxycoccus was in the lower zone $\left(\chi^{2}=0.068, \mathrm{df}=1, \mathrm{p}=0.794\right)$. After 24 $\mathrm{h}$, six of ten larvae were on a paper towel and the others on V. uliginosum (12.5 to $14 \mathrm{~cm})$.

\section{Food preferences of larvae of the bog ecotype after overwintering}

In the spring, B. eunomia larvae in the final instar were observed sitting or wandering on sphagnum moss or feeding on $V$. oxycoccus on the raised bog in the Jesionowe Góry reserve. After relocation to the laboratory, they fed not only on $V$. oxycoccus, but also on P. bistorta and pupated successfully, producing normal adults.

\section{DISCUSSION}

The results revealed differences in the host plant relationships of the two ecotypes of B. eunomia. First of all,
A

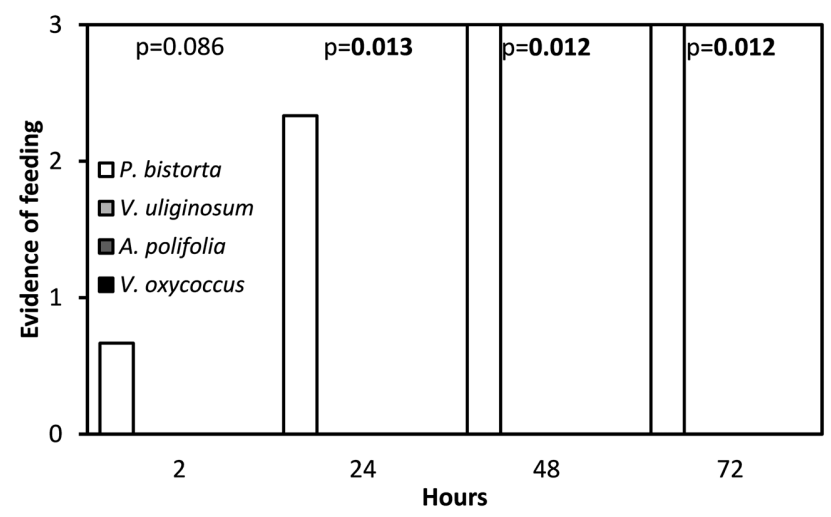

B

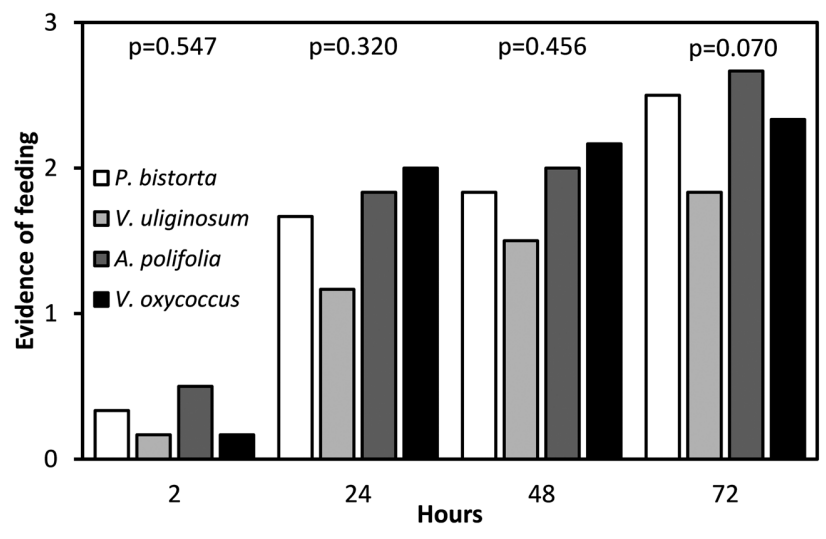

Fig. 6. Averaged incidences of feeding by larvae of Boloria eunomia of the (A) meadow and the (B) bog ecotypes on four species of plants in the 'host plant selection test'. Incidences of feeding were assessed on a 4-point scale. $p$ - asymptotic significance, twosided test according to Kruskal-Wallis test. Statistically significant values are in bold.

larvae of the meadow ecotype were only able to develop on a plant found in their typical habitat, P. bistorta. In contrast, larvae of the bog ecotype were able to develop successfully on three species of the family Ericaceae (occurring on raised bogs) and $P$. bistorta prior to overwintering. The development of the larvae of the bog ecotype could not be fully traced in laboratory conditions due to very high mortality. However, larvae found in the spring in the field on $V$. oxycoccus were able to complete their development even after changing their diet to P. bistorta. This ecotype, unlike the meadow ecotype, showed no significant preference for the four plants (three Ericaceae species and $P$. bistorta) provided. Phylogeographic studies indicate that the bog fritillary evolved in the Siberian tundra, where $P$. bistorta and $P$. vivipara were both abundant in the past (Maresova et al., 2019). Our results are consistent with these findings and may confirm that P. bistorta was indeed one of the original larval food plants of this butterfly and only later did some populations adapt to feeding on other species of plants when colonizing new biotopes in cold climates. It is known that the switch to other host plants in insects can lead to the colonization of new kinds of habitats (Strausz et al., 2012) or range expansion (Tabashnik, 1983; 


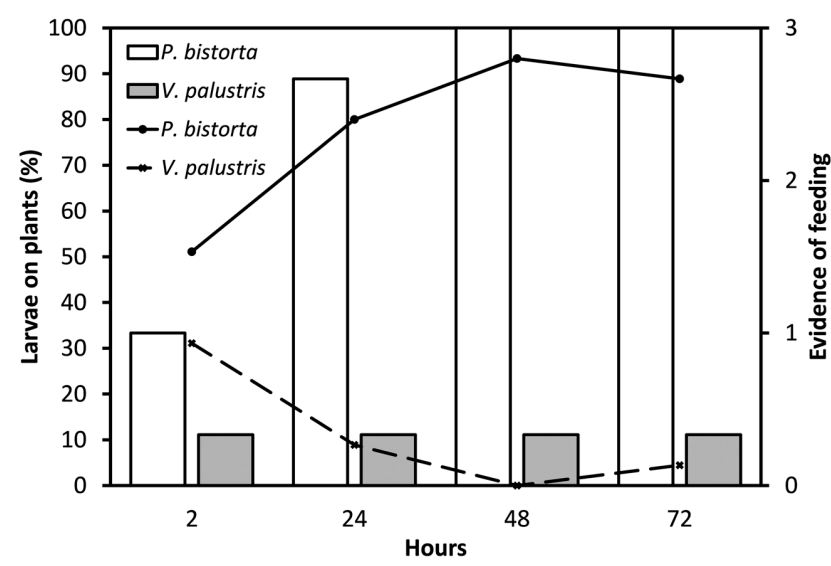

Fig. 7. Averaged percentage of larvae on plants (line graphs) and averaged incidences of feeding (bar graphs) in the "host plant selection test' for larvae of the meadow ecotype of Boloria eunomia provided with two species of plants. All differences (except those observed after just two hours) between the two species of plants were significant $(p<0.05$ asymptotic significance, two-sided test according to Mann-Whitney $U$ test).

Tabashnik et al., 1981). Depending on the degree of the systematic relationship between the original and novel species of host plants the divergence in butterfly populations can be weaker or stronger and even speciation may occur (Bush, 1969; Rausher, 1982; Tabashnik, 1983; HernándezRoldán et al., 2016).

The bog ecotype from north-eastern Poland is potentially polyphagous and retains its ability to feed on P. bistorta. This raises the question whether individuals from bog populations could occupy meadow habitats and how they would behave, i.e., whether a female would be able to oviposit on P. bistorta? The results of comparative studies on oviposition and larval food preferences of two related species of Polygonia indicate that larvae may be more conservative than females irrespective of differences in their dispersal activity (Nylin et al., 2015).

We also used two other potential host plants of $B$. eunomia, $V$. palustris and $S$. aurita, in our experiments. In contrast to the bog ecotype, larvae of the meadow ecotype started to feed on V. palustris, but only two of them reached the second instar. Although this plant is mentioned in the literature as the larval food plant of B. eunomia (Scott, 1986; Tolman, 1997; Haahtela et al., 2006), there is no precise data (e.g. on regions and habitats) for these records. Simonsen (2006) hypothesizes that species of Violaceae were host plants of an ancestor of the genus Boloria and in some cases, a switch to other host plants occurred. Willows are cited as larval food plants in North America (Shepard, 1975; Scott, 1986; Bird et al., 1995) and in our studies $S$. aurita was eaten by the larvae of both ecotypes, but they did not grow. Therefore, also taking into consideration the phylogenetic relationships between populations from both continents (Maresova et al., 2019), it is doubtful that willows could be utilized by B. eunomia in Europe.

The second fundamental difference between the two ecotypes of $B$. eunomia is the survival of their larvae. The larvae of the meadow ecotype reared on their 'native' plant,
P. bistorta, survived significantly better than larvae of the bog ecotype provided with both Ericaceae and P. bistorta. The survival of the meadow ecotype was comparable with that reported in studies carried out in Belgium (Radchuk et al., 2013). In the case of larvae of the bog ecotype survival on the different plants differed with the highest survival recorded on $V$. uliginosum and lowest on $V$. oxycoccus. This is not consistent with the field observations on both larval behaviour and oviposition reported by Klimczuk \& Sielezniew (2017). The choice of $V$. oxycoccus under natural conditions may be associated with other factors. There are many cases of the use suboptimal host plants by larvae (García-Barros \& Fartmann, 2009). For example, as a result of habitat specialization females of Lycaena dispar batavus most likely accept a poorer host plant limited to a particular fenland habitat (Martin \& Pullin, 2004).

The preference of $B$. eunomia for $V$. oxycoccus in northeastern Poland under natural conditions may be associated with thermoregulation. V. oxycoccus, unlike other Ericaceae, is a low growing and decumbent plant, which almost adheres to the moss layer. The role of sphagnum moss in thermoregulation is demonstrated by studies on a related species of butterfly, the cranberry fritillary Boloria aquilonaris, whose larvae only feed on $V$. oxycoccus (Turlure et al., 2011). However, it cannot be excluded that B. eunomia larvae may also use other plants, like $V$. uliginosum and $A$. polifolia, if they grow nearby. Our results show that despite the tendency of larvae to remain on $V$. oxycoccus they are able to climb up and occupy $V$. uliginosum.

Both our laboratory and field observations indicate that the larvae of $B$. eunomia are relatively mobile. It was also noted that some first instar larvae in the 'host plant selection test' remained on plants on which they did not feed. Hence, the results for 'evidence of feeding' were more repetitive and consistent than the 'percentage of larvae on plants', although the latter clearly differed between the ecotypes.

The two forms of Boloria eunomia probably also differ in their larval behaviour due to differences in their oviposition strategy. Females of the meadow ecotype lay several eggs in a loose cluster (Choutt et al., 2011; Radchuk et al., 2013) and as a consequence young larvae live gregariously before overwintering (Turlure et al., 2009). In contrast, the larvae of the bog ecotype are probably solitary throughout their development since females of this ecotype lay their eggs singly (Klimczuk \& Sielezniew, unpubl.).

The poor survival of the larvae of the bog ecotype recorded in captivity supports the hypothesis based on studies of the adult population ecology of B. eunomia, which indicate that the bog ecotype is more vulnerable. Therefore, it may be more threatened with extinction than the meadow ecotype, at least, in this part of its distribution (Sielezniew et al., 2019). Observations carried out during rearing indicate that the high mortality of the larvae of the bog ecotype may be associated with the longer activity period between egg hatch and overwintering.

There were also clear differences in larval development of the two ecotypes. Larvae of the meadow ecotype entered 
diapause in the third instar, that is after 20-30 days, whereas larvae of the bog ecotype developed slightly more slowly, and some of them moulted to the fourth instar. Although in 2018 , the majority of the larvae of the meadow ecotype became active again at the end of summer, a very small proportion of them entered the fourth instar compared to the bog ecotype. This could be related to different microclimatic conditions in the two biotopes, i.e., raised bogs are generally cooler. Therefore, the emergence of adults in an optimum period, when Rhododendron tomentosum (a favourite nectar plant) is in full bloom, may have resulted in developmental period prior to overwintering being more prolonged. Developmental differences as an adaptation to phenology of host plants are reported, e.g., in Phengaris alcon (Sielezniew \& Stankiewicz, 2007).

Unexpectedly in 2018, three fourth-instar larvae of the meadow ecotype moulted again and completed their development with two second generation individuals emerging. In the same season, which was generally very warm with some butterflies in the region showing phenological peculiarities (Klimczuk \& Sielezniew, unpubl.), a second generation of B. eunomia also developed under natural conditions. Two males of this species were observed on the $21 \mathrm{st}$ of September at a site in the Knyszyn Forest. This was the first such record for Poland. Second-generation individuals are reported in Germany (Schneider, 1935). However, in the case of the larvae of the bog ecotype, none moulted to the fifth instar, although they reached the fourth instar earlier than the larvae of the meadow ecotype.

\section{CONCLUSIONS}

This study is the first attempt to compare the larval food preferences of two ecotypes of $B$. eunomia. It was carried out in a unique region where different evolutionary lineages of the butterfly co-occur (Maresova et al., 2019). We demonstrate the ability of larvae of the bog ecotype to develop on $P$. bistorta, a host plant native of the meadow ecotype. On the other hand, larvae of the meadow ecotype developed only on $P$. bistorta. Our laboratory experiments indicate, however, that $V$. oxycoccus is not an optimal host for the bog ecotype although it seems to be preferred in the field. Moreover, in north-eastern Poland, larvae of the meadow ecotype overwinter mainly in the third instar, whereas the larvae of the bog ecotype enter diapause mostly in the fourth instar. This is most likely an adaptation to the local microclimate and phenology of the favourite nectar plant ( $R$. tomentosum). The higher larval mortality of the bog ecotype indicates it is more vulnerable than the meadow ecotype. On the other hand, it is likely that the meadow ecotype has some potential to adapt to a warming climate, as it can produce a partial second generation.

ACKNOWLEDGEMENTS. We thank R. Porzak for help with the statistical analyses. N. Ochman improved the earlier draft of the manuscript linguistically. This research was funded by the Polish Ministry of Science and Higher Education, which provided a subsidy for maintaining the research potential of the Faculty of Biology, University of Bialystok. Two anonymous reviewers made valuable comments on the manuscript.

\section{REFERENCES}

Bergman K.-O. 1999: Habitat utilization by Lopinga achine (Nymphalidae: Satyrinae) larvae and ovipositing females: implications for conservation. - Biol. Conserv. 88: 69-74.

Bird C.D., Hilchie G.J., Kondla N.G., Pike E.M. \& Sperling F.A.H. 1995: Alberta Butterflies. The Provincial Museum of Alberta, Edmonton, 349 pp.

Burghardt F. \& Fiedler K. 1996: The influence of diet on growth and secretion behaviour of myrmecophilous Polyommatus icarus caterpillars (Lepidoptera: Lycaenidae). - Ecol. Entomol. 21: 1-8.

Bush G.L. 1969: Sympatric host race formation and speciation in frugivorous flies of the genus Rhagoletis (Diptera, Tephritidae). - Evolution 23: 237-251.

Buszko J. 1997: Moths of Poland. Part 2. Lasiocampidae, Sphingidae, Actiidae. IMAGE, Warszawa, 262 pp. [in Polish].

Choutt J., Turlure C., Baguette M. \& Schtickzelle N. 2011: Parasitism cost of living in a high quality habitat in the bog fritillary. - Biodiv. Conserv. 20: 3117-3131.

Cleary D.F.R., Descimon H. \& Menken S.B.J. 2002: Genetic and ecological differentiation between the butterfly sister species Colias alfacariensis and Colias hyale. - Contrib. Zool. 71: 131-139.

DörIng E. \& HofFMANN M.H. 2004: Distribution analysis of monophagous butterflies (Lepidoptera) and their host plants in the western Palearctic. - Schlechtendalia 12: 85-93.

García-Barros E. \& Fartmann T. 2009: Butterfly oviposition: sites, behaviour and modes. In Settele J., Shreeve T., Konvička M. \& Dyck H. van (eds): Ecology of Butterflies in Europe. Cambridge University Press, Cambridge, pp. 29-42.

Gillespie M. \& WratTen S.D. 2011: Oviposition preference of Lycaena salustius for, and larval performance on, a novel host plant: an example of ecological fitting. - Ecol. Entomol. 36: 616-624.

Graves S.D. \& Shapiro A.M. 2003: Exotics as host plants of the California butterfly fauna. - Biol. Conserv. 110: 413-433.

Grundel R., Pavlovic N.B. \& Sulzman C.L. 1998: Habitat use by the endangered Karner blue butterfly in oak woodlands: the influence of canopy cover. - Biol. Conserv. 85: 47-53.

Haahtela T., SaArinen K., Ojalainen P. \& Aarnio H. 2006: Butterflies. Finland, Nordic Countries, Baltics. Kustannusosakeyhtiö Tammi, Helsinki, 248 pp. [in Finnish].

Hernández-Roldán J.L., Dapporto L., Dincă V., Vicente J.C., Hornett E.A., Šíchová J., LuKhtanov V.A., Talavera G. \& VILA R. 2016: Integrative analyses unveil speciation linked to host plant shift in Spialia butterflies. - Mol. Ecol. 25: 42674284.

JANZ N. 2005: The relationship between habitat selection and preference for adult and larval food resources in the polyphagous butterfly Vanessa cardui (Lepidoptera: Nymphalidae). J. Insect Behav. 18: 767-780.

Joshi A. \& THompson J.N. 1995: Trade-offs and the evolution of host specialization. - Evol. Ecol. 9: 82-92.

KLIMCZuK P. 2011: Butterflies (Lepidoptera: Hesperioidea, Papilionoidea) of the Knyszyn Forest (Puszcza Knyszyńska) and adjacent woodland areas of Białystok - in the years 1995-2010. - Fragmenta Naturae (formerly Nature Journal) 44: 197-217.

KlimczuK P. \& SielezNiew M. 2017: Unexpected differencies in butterfly diversity between two peat bogs in the same area. Pol. J. Entomol. 86: 251-273.

LaPlante J.P. 1985: Papillons et Chenilles du Québec et de l'Est $d u$ Canada. Editions France-Amérique, Montréal, 279 pp. [in French]. 
Layberry R.A., Hall P.W. \& Lafontaine J.D. 1998: The Butterflies of Canada. Univesity of Toronto Press, Toronto, Buffalo, London, $354 \mathrm{pp}$.

Maresova J., Habel J.S., Neve G., Sielezniew M., Bartonova A., Kostro-AmbroziaK A. \& Fric Z.F. 2019: Cross-continental phylogeography of two Holarctic Nymphalid butterflies, Boloria eunomia and Boloria selene. - PLoS ONE 14(3): e0214483, 22 pp.

Martin L.A. \& Pullin A.S. 2004: Host-plant specialisation and habitat restriction in an endangered insect, Lycaena dispar batavus (Lepidoptera: Lycaenidae) I. Larval feeding and oviposition preferences. - Eur. J. Entomol. 101: 51-56.

Meister H., Lindman L. \& Tammaru T. 2015: Testing for local monophagy in the regionally oligophagous Euphydryas aurinia (Lepidoptera: Nymphalidae). - J. Insect Conserv. 19: 691-702.

NeKola J.C. 1998: Butterfly (Lepidoptera: Lycaenidae, Nymphalidae, and Satyridae) faunas of three peatland habitat types in the Lake Superior Drainage Basin of Wisconsin. - Great Lakes Entomol. 31: 27-38.

Noreika N., Kotze D.J., Loukola O.J., Sormunen N., Vuori A., Päivinen J., Penttinen J., Punttila P. \& Kotiaho J.S. 2016: Specialist butterlies benefit most from the ecological restoration of mires. - Biol. Conserv. 196: 103-114.

NyLIN S. 1988: Host plant specialization and seasonality in a polyphagous butterfly, Polygonia c-album (Nymphalidae). Oikos 53: 381-386.

Nylin S., Söderlind L., Gamberale-Stille G., Audusseau H., Celorio-Mancera M.D., Janz N. \& Sperling F.A.H. 2015: Vestiges of an ancestral host plant: preference and performance in the butterfly Polygonia faunus and its sister species P. c-album. - Ecol. Entomol. 40: 307-315.

Quinn R.M., Gaston K.J. \& Roy D.B. 1998: Coincidence in the distribution of butterflies and their food plants. - Ecography 21: $279-288$.

Radchuk V., Turlure C. \& Schtickzelle N. 2013: Each life stage matters: the importance of assessing the response to climate change over the complete life cycle in butterflies. - J. Anim. Ecol. 82: 275-285.

RAusHer M.D. 1982: Population differentiation in Euphydryas editha butterflies: larval adaptation to different hosts. - Evolution 36: 581-590.

SCHNEIDER C. 1935: Argynnis aphirape Hbn. Verbreitung in Württemberg, Beschreibung einer 2. Generation. - Int. Entomol. Z. 29: 289-291 [in German].

Scotт J.A. 1986: The Butterflies of North America. A Natural History and Field Guide. Stanford University Press, Stanford, CA, 584 pp.

ShePARD J.H. 1975: Genus Boloria Reuss. In Howe W.H. (ed.): The Butterflies of North America. Doubleday, Garden City, NY, pp. 243-252.
Sielezniew M. \& Stankiewicz A.M. 2007: Differences in the development of the closely related myrmecophilous butterflies Maculinea alcon and M. rebeli (Lepidoptera: Lycaenidae). Eur. J. Entomol. 104: 433-444.

Sielezniew M. \& Stankiewicz-Fiedurek A.M. 2013: Behavioural evidence for a putative oviposition-deterring pheromone in the butterfly, Phengaris (Maculinea) teleius Lepidoptera (Lycaenidae). - Eur. J. Entomol. 110: 71-80.

Sielezniew M., Kostro-Ambroziak A., Kuimczuk P., Deoniziak K., PAŁKa K. \& Nowicki P. 2019: Habitat-related differences in the adult longevity of two ecotypes of a specialized butterfly. - J. Zool. 307: 93-103.

Simonsen T.J. 2006: Fritillary phylogeny, classification, and larval host plants: reconstructed mainly on the basis of male and female genitalic morphology (Lepidoptera: Nymphalidae: Argynnini). — Biol. J. Linn. Soc. 89: 627-673.

Singer M.C. \& PARMESAn C. 2018: Lethal trap created by adaptive evolutionary response to an exotic resource. - Nature 557: 238-241.

Strausz M., Fiedler K., Franzén M. \& Wiemers M. 2012: Habitat and host plant use of the Large Copper Butterfly Lycaena dispar in an urban environment. - J. Insect Conserv. 16: 709-721.

Švitra G. \& Sielezniew M. 2010: The first observation of Euphydryas aurinia (Lepidoptera, Nymphalidae) developing on Gentiana cruciata in Lithuania. - Pol. J. Entomol. 79: 195-201.

TABASHNIK B.E. 1983: Host range evolution: the shift from native legume hosts to alfalfa by the butterfly, Colias philodice eriphyle. - Evolution 37: 150-162.

Tabashnik B.E., Wheelock H., Rainbolt J.D. \& Watt W.B. 1981: Individual variation in oviposition preference in the butterfly, Colias eurytheme. - Oecologia (Berlin) 50: 225-230.

Thompson J.N. \& Pellmyr O. 1991: Evolution of oviposition behaviour and host preference in Lepidoptera. - Annu. Rev. Entomol. 36: 65-89.

Tolman T. 1997: Collins Field Guide. Butterflies of Britain and Europe. Harper Collins, London, 320 pp.

Turlure C., Dyck H. van, Schtickzelle N. \& Baguette M. 2009: Resource-based habitat definition, niche overlap and conservation of two sympatric glacial relict butterflies. - Oikos 118: 950-960.

Turlure C., Radchuk V., Baguette M., Dyck H. van \& SchtickZELLE N. 2011: On the significance of structural vegetation elements for caterpillar thermoregulation in two peat bog butterflies: Boloria eunomia and B. aquilonaris. - J. Therm. Biol. 36: $173-180$.

Received February 4, 2020; revised and accepted August 17, 2020 Published online October 7, 2020

Supplementary material follows (Tables S1-S5, Figs S1-S3). 
Table S1. Statistical comparison of the survival of the larvae before overwintering of two ecotypes of $B$. eunomia. Mann-Whitney $\mathrm{U}$ test. See Fig. 1 in the main text. $\mathrm{m}$ - meadow ecotype, $\mathrm{b}$ - bog ecotype. Statistically significant values are in bold.

\begin{tabular}{lcccc}
\hline Plant species & Year & $\mathrm{N}$ & Statistics (U) Significance $(\mathrm{p})$ \\
\hline P. bistorta & 2017 & $100(27 \mathrm{~m}, 73 \mathrm{~b})$ & 562.000 & $\mathbf{0 . 0 0 1}$ \\
& 2018 & $390(302 \mathrm{~m}, 88 \mathrm{~b})$ & 2941.500 & $<\mathbf{0 . 0 0 1}$ \\
\hline V. palustris & 2018 & $126(94 \mathrm{~m}, 32 \mathrm{~b})$ & 32.000 & $<\mathbf{0 . 0 0 1}$ \\
\hline \multirow{2}{*}{ V. oxycoccus } & 2017 & $86(33 \mathrm{~m}, 53 \mathrm{~b})$ & 1704.500 & $<\mathbf{0 . 0 0 1}$ \\
& 2018 & $140(10 \mathrm{~m}, 130 \mathrm{~b})$ & 876.000 & 0.066 \\
\hline \multirow{2}{*}{ V. uliginosum } & 2017 & $43(9 \mathrm{~m}, 34 \mathrm{~b})$ & 222.000 & $\mathbf{0 . 0 3 8}$ \\
\hline \multirow{2}{*}{ A. polifolia } & 2018 & $86(7 \mathrm{~m}, 79 \mathrm{~b})$ & 444.000 & $\mathbf{0 . 0 0 8}$ \\
\hline S. aurita & 2017 & $41(11 \mathrm{~m}, 30 \mathrm{~b})$ & 293.000 & $<\mathbf{0 . 0 0 1}$ \\
\hline
\end{tabular}

Table S2. Statistical analysis of the percentage of larvae on plants in the 'host plant selection test' (the four plants were: Persicaria bistorta, Vaccinium oxycoccus, V. uliginosum and Andromeda polifolia). The results of Kruskal-Wallis test. See Fig. 5 in the main text. Statistically significant values are in bold.

\begin{tabular}{lccc}
\hline Boloria eunomia ecotype & Hours & Statistics $(\mathrm{H})$ & Significance $(\mathrm{p})$ \\
\hline \multirow{3}{*}{ Meadow } & 2 & 0.360 & 0.948 \\
& 24 & 6.080 & 0.108 \\
& 48 & 8.230 & $\mathbf{0 . 0 4 1}$ \\
& 72 & 8.214 & $\mathbf{0 . 0 4 2}$ \\
\hline \multirow{3}{*}{ Bog } & 2 & 2.920 & 0.404 \\
& 24 & 11.570 & $\mathbf{0 . 0 0 9}$ \\
& 48 & 3.797 & 0.284 \\
& 72 & 3.358 & 0.340 \\
\hline
\end{tabular}

Table S3. Statistical analysis of the evidence of feeding by larvae on plants in the 'host plant selection test' (the four plants were: Persicaria bistorta, Vaccinium oxycoccus, V. uliginosum and Andromeda polifolia). The results of Kruskal-Wallis test. See Fig. 6 in the main text. Statistically significant values are in bold.

\begin{tabular}{lccc}
\hline Boloria eunomia ecotype & Hours & Statistics $(\mathrm{H})$ & Significance $(\mathrm{p})$ \\
\hline \multirow{3}{*}{ Meadow } & 2 & 6.600 & 0.086 \\
& 24 & 10.800 & $\mathbf{0 . 0 1 3}$ \\
& 48 & 11.000 & $\mathbf{0 . 0 1 2}$ \\
& 72 & 11.000 & $\mathbf{0 . 0 1 2}$ \\
Bog & 2 & 2.126 & 0.547 \\
& 24 & 3.504 & 0.320 \\
& 48 & 2.606 & 0.456 \\
& 72 & 7.056 & 0.070
\end{tabular}

Table S4. Statistical analysis of the results of the host plant selection test using larvae of the meadow ecotype of Boloria eunomia and two species of plants (Persicaria bistorta and Viola palustris). The results of the Mann-Whitney $U$ test. See Fig. 7 in the main text. Statistically significant values are in bold.

\begin{tabular}{lccc}
\hline Parameter & Hours & Statistics $(U)$ & Significance $(p)$ \\
\hline & 2 & 2.000 & 0.275 \\
Percentage of larvae & 24 & 0.000 & $\mathbf{0 . 0 4 6}$ \\
on plants & 48 & 0.000 & $\mathbf{0 . 0 3 7}$ \\
& 72 & 0.000 & $\mathbf{0 . 0 4 6}$ \\
\hline \multirow{2}{*}{ Evidence of feeding } & 2 & 1.500 & 0.114 \\
& 24 & 0.000 & $\mathbf{0 . 0 4 3}$ \\
& 48 & 0.000 & $\mathbf{0 . 0 3 4}$ \\
& 72 & 0.000 & $\mathbf{0 . 0 3 4}$ \\
\hline
\end{tabular}

Table S5. Distance matrix of differences in survival of larvae without (above diagonal) and with (below diagonal) the number of individuals in consecutive stages of development included among the five groups tested. See Fig. 2 in the main text.

\begin{tabular}{|c|c|c|c|c|c|}
\hline Group tested & Meadow P. bistorta & Bog V. oxycoccus & Bog V. uliginosum & Bog A. polifolia & Bog P. bistorta \\
\hline Meadow P. bistorta & - & 519147 & 498307 & 574182 & 542034 \\
\hline Bog V. oxycoccus & 114.144 & - & 11874 & 16029 & 3903 \\
\hline Bog V. uliginosum & 122.687 & 43.474 & - & 3143 & 3927 \\
\hline Bog A. polifolia & 108.644 & 22.188 & 21.493 & - & 4616 \\
\hline Bog P. bistorta & 111.074 & 18.341 & 28.855 & 9.100 & - \\
\hline
\end{tabular}

Fig. S1 (next page). Photographs showing live larvae and evidence of their feeding activity before overwintering. a - 5th (final) instar larva of the meadow ecotype feeding on Persicaria bistorta 99 days after hatching (photographed on 21st September 2018); b - 1st instar larvae of the meadow ecotype on Viola palustris; c-1st instar larvae of the bog ecotype on Vaccinium oxycoccus; $\mathrm{d}-2 \mathrm{nd}$ and 3rd instar larvae of the bog ecotype on Andromeda polifolia; e - 2nd (mostly) and 3rd instar larvae of the bog ecotype on V. uliginosum; $f$ - 1 st instar larvae of the bog ecotype on P. bistorta; $\mathrm{g}-2 \mathrm{nd}$ instar larvae of the bog ecotype on $V$. myrtillus; $\mathrm{h}-1$ st instar larvae of the bog ecotype feeding on Salix aurita. 

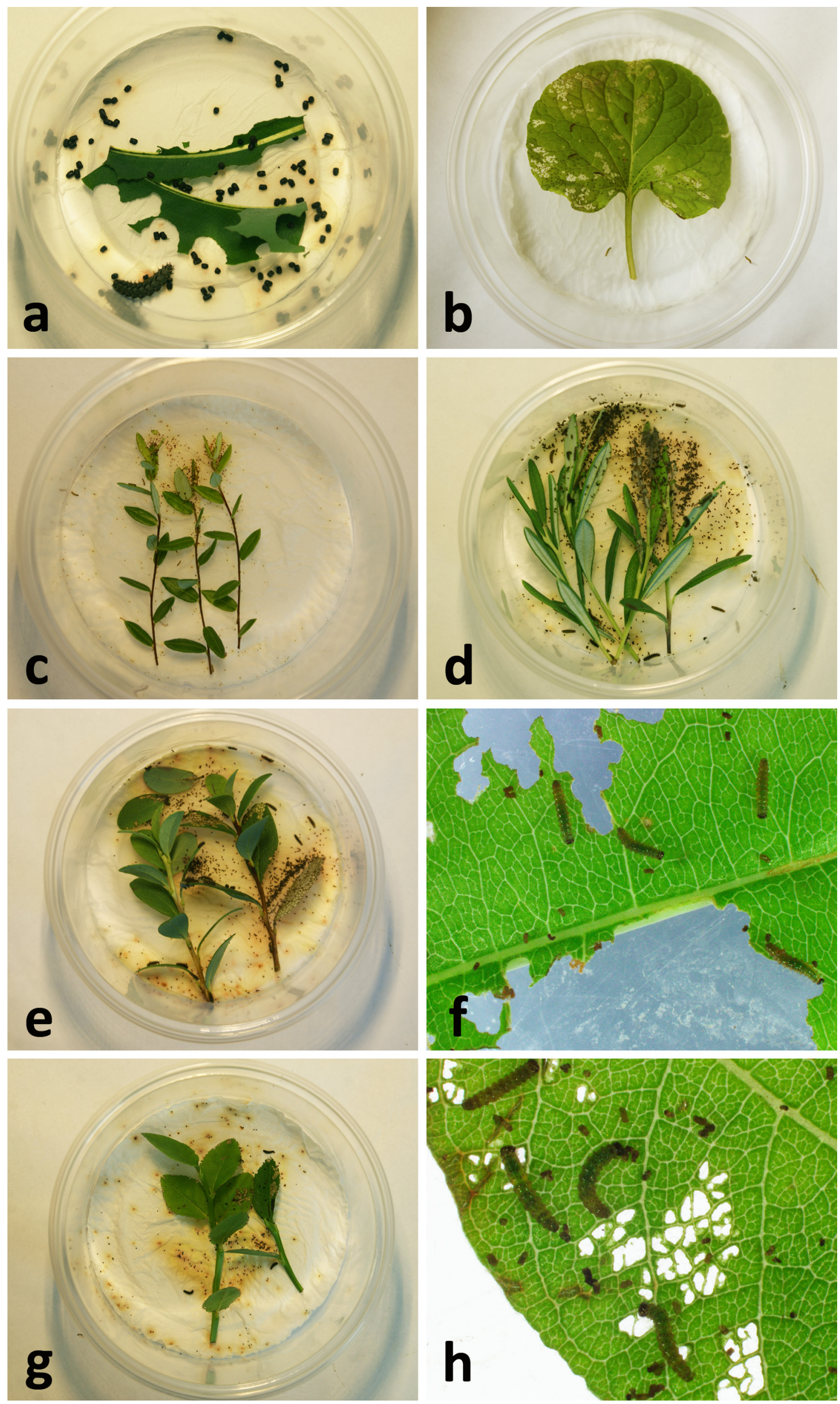

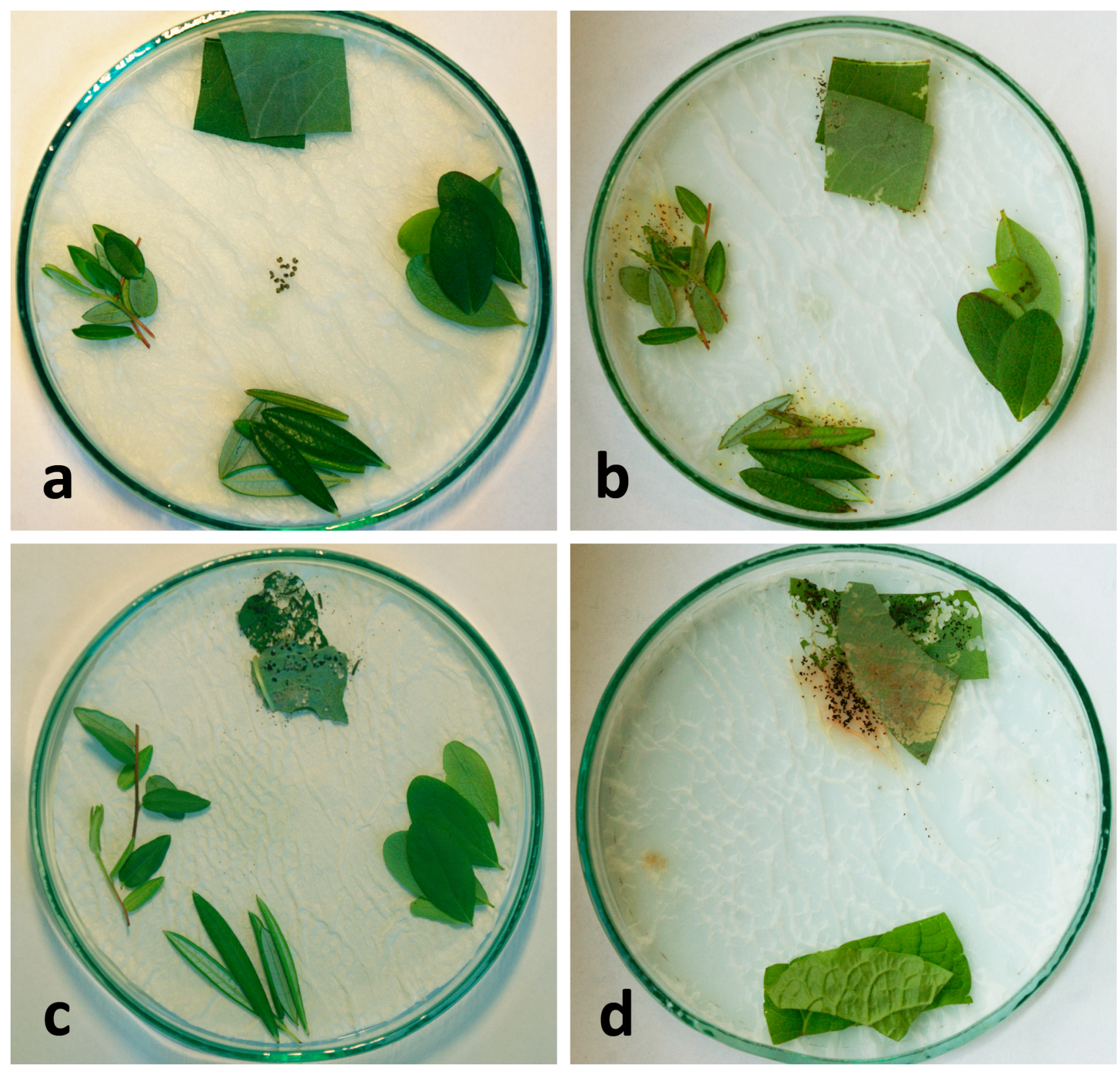

Fig. S2. Photographs of the host plant selection test. a - newly hatched larvae of the bog ecotype just after placing them in the centre of the Petri dish, $\mathrm{b}$ - larvae of the bog ecotype after $48 \mathrm{~h}$ (there is evidence of their having fed on all four plants, P. bistorta, V. uliginosum, A. polifolia and $V$. oxycoccus), c - larvae of the meadow ecotype after $48 \mathrm{~h}$ (evidence of feeding only on $P$. bistorta), $\mathrm{d}$ - larvae of the meadow ecotype after $72 \mathrm{~h}$ in the two-plant version of the experiment (evidence of feeding on P. bistorta, but not on $V$. palustris). 

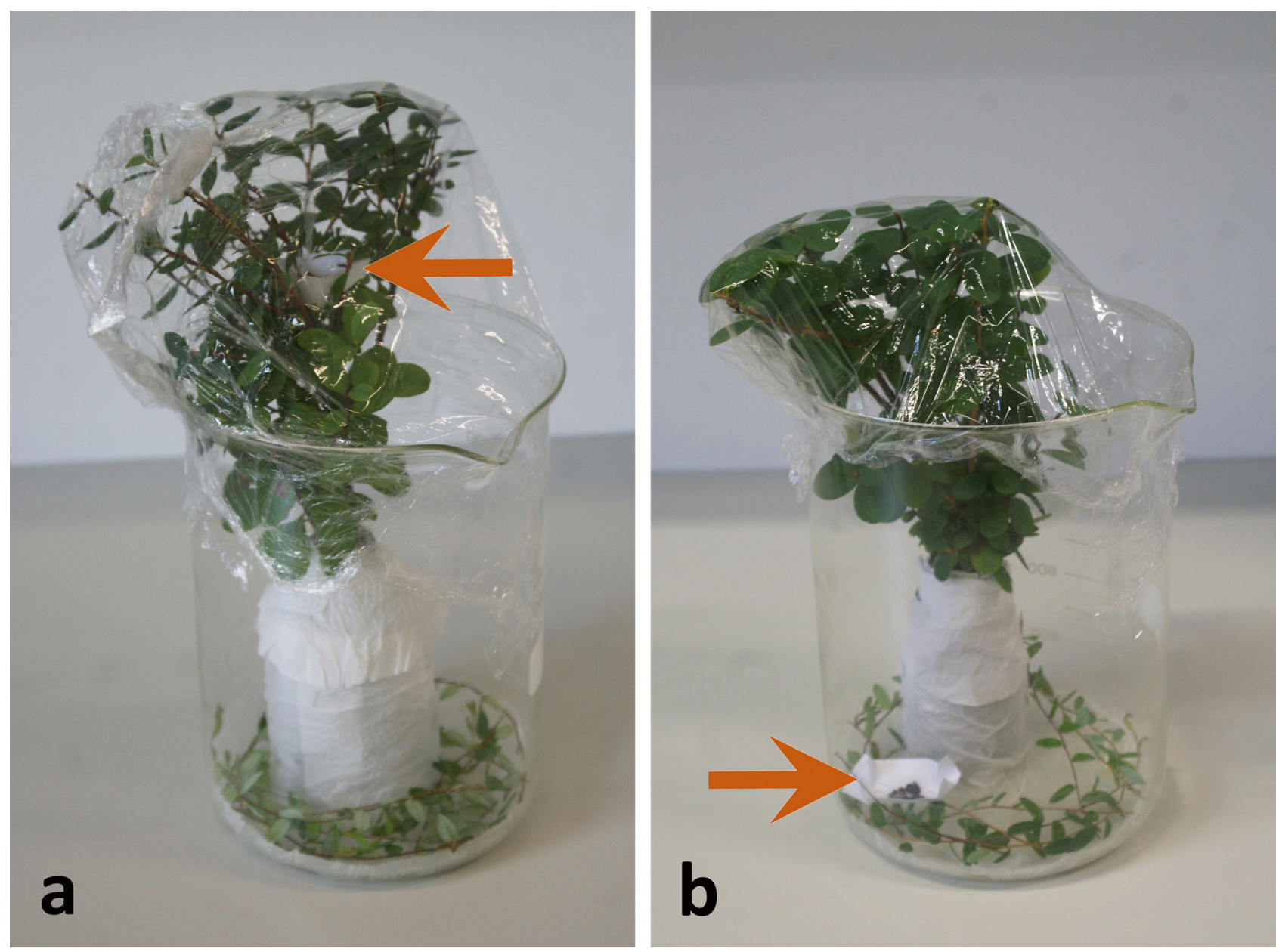

Fig. S3. Photographs of larval food preferences in the 'vertical movement' experiment. a - larvae placed on Vaccinium uliginosum, $\mathrm{b}-$ larvae placed on Vaccinium oxycoccus. Arrows indicate small paper trays with larvae. 